\title{
Learning Environment of Basic Health Sciences in Private (Integrated) versus Public (Traditional Curriculum) Medical Schools during COVID-19
}

Anila Jaleel', Kiran Namoos', Samar Asim ${ }^{2}$, Khizra Afzal ${ }^{3}$, Hamail Barkat $^{3}$, Amna Afzal ${ }^{3}$, Ayla Siddiqui ${ }^{4}$ 'Department of Biochemistry, Shalamar Medical and Dental College, Lahore, ${ }^{2}$ Department of Pulmonology, Shalamar Medical and Dental College, Lahore, ${ }^{3} S t u d e n t$ Shalamar Medical and Dental College, Lahore, Pakistan, ${ }^{4}$ Student, Texas Christian University, Texas, USA.

\begin{abstract}
Background: Educational environment (EE) plays a pivotal role in the academic growth of a medical student. The objective of the study was to compare the perception of a learning environment in Basic Health Sciences by first and second-year MBBS students of private and public medical colleges in Lahore, Pakistan during Covid-19 using a questionnaire.
\end{abstract}

Methods: Data was collected from students (146) through a self-reported questionnaire via Google. dox after obtaining consent. A total score between 151 and 200 was considered excellent. A score between 101 and 150 indicated a positive approach while less than 100 was considered problematic. A score $\geq 3.5$ for individual items indicate the presence of the specific aspect of the educational environment, whereas, $<3$ score requires attention. The t-test was used for analysis and $p<0.05$ was considered significant.

Results: Out of 146 students $84(51.21 \%)$ were from private medical colleges while $62(42.46 \%)$ were from public medical colleges. The students of private medical colleges who follow the integrated curriculum found the learning sessions (27.84 \pm 7.40$)$ were more student-centered with supporting online classes $(2.75 \pm 1.01)(p<0.05)$. Multiple softwares found that the tutorial sessions improved their problem-solving skills $(>2.5)$. Teachers were helpful in stress management during the pandemic ( $>3$ ). Proper counselors were employed by the private medical schools to cater to the needs of students who required assistance.

Conclusion: A significantly high mean score was obtained from private-sector medical students regarding students' perception of learning (SPL), students' perception of teachers (SPT), and students' academic self-perception (SASP), compared to public medical colleges.

Keywords: Learning Environment; Questionnaire; Medical Students; Perception; Integrated.

\section{Corresponding Author:}

\section{Dr. Anila Jaleel}

Department of Biochemistry,

Shalamar Medical and Dental College.

Lahore, Pakistan.

Email: anilajaleel@gmail.com

https://doi.org/10.36283/PJMD11-1/016

How to cite: Jaleel A, Namoos K, Asim S, Afzal K, Barkat H, Afzal A, et al. A Learning Environment of Basic Health Sciences in Private (Integrated) versus Public (Traditional Curriculum) Medical Schools during COVID-19. 2022;11(1): 94-100. doi: 10.36283/PJMD11-1/016 


\section{INTRODUCTION}

The educational environment (EE) of any academic institute plays a pivotal role in the academic growth of a medical student and the ultimate success of an individual'. It refers to various physical sets, contexts, and values in which students receive education and perceive their surroundings. EE is determined by factors such as curriculum, teachers, peers, learning provisions, the atmosphere of the institute, and physical settings ${ }^{2}$. Because medical education can be extremely tiring, burdensome, and stressful, students' learning environment is directly proportional to their wellbeing ${ }^{3}$. The learning environment of any institution has a direct effect on the quality of its students 4,5 .

All private and public sectors of medical colleges in Pakistan offer a five-year MBBS degree program. The first two years focus purely on teaching basic health sciences considering clinical settings; meanwhile, the third, fourth, and final years of education focus on empowering students with skills as problem-solving, diagnosis, and management in clinical settings ${ }^{6}$. There is a shift in educational trends from a traditional, nonintegrated, teacher-centered approach to an integrated, student-centered approach in most of the private and few public medical schools in Pakistan.

These medical schools follow an integrated teaching approach, utilizing various teaching methodologies like PBLs (Problem Based Learning), SGDs (Small Group Discussions), tutorials, laboratory sessions, and interactive lectures. However, most public medical schools still follow traditional (subject-based) curricula with each department separately focusing on basic subjects, lectures being the prime focus. To evaluate the learning environment, we intend to conduct a study using DREEM's (Dundee Ready Education Environment Measure) questionnaire. Several studies have been conducted using DREEM inventory. It was used to compare learning environments across various institutes ${ }^{7-14}$. The objective of the study was to compare the perception of the learning environment in Basic Health Sciences by first and second-year MBBS students of private and public medical colleges in Lahore, Pakistan during the Covid-19.

\section{METHODS}

The study included $n=146$ students of first and second-year MBBS from private and public medical schools of Lahore, Pakistan. It was a cross-sectional study conducted at Shalamar Medical and Dental College between March 2020 to January 2021. The study was approved by Institutional Review Board, Shalamar Medical and Dental College. Partial in-class and online classes were being conducted for students during this period due to intermittent closure of institutes due to the rise in COVID 19 cases. A convenient sampling technique was used. Ethical approval was obtained from the IRB committee of Shalamar Medical and Dental College. The students who were currently enrolled and attending first and second-year MBBS classes in private and public medical colleges were included.

Private medical colleges with an integrated curricuIum and public medical colleges with a traditional curriculum participated in the study. Students pursuing third, fourth and final year MBBS and those who refused to participate in the study were excluded. Information was collected from students through a self-reported questionnaire via Google Dox ${ }^{15}$. They were asked to provide their actual opinion to make research constructive, and a consent form for their agreement was provided. Statistical analyses were done using a statistical package for social sciences (SPSS) $\vee$ 20.0. Mean and standard deviations (SD) were calculated for each separate item. The t-test was used for data analysis and $p$-value $<0.05$ was considered statistically significant.

\section{RESULTS}

Out of 146 students that participated in the study, 84 $(51.21 \%)$ belonged to private medical colleges while 62 (42.46\%) belonged to public medical colleges. The learning environment in both types of medical schools i.e., private and public was perceived as positive and conducive. Figure 1 shows the mean scores of various subscales of the questionnaire in two types of institutes. The overall mean of all five domains was $122.60 \pm 29.31$ and $111.48 \pm 25.16$ in private and public medical schools respectively. Scores of students' perception of learning, students' perception of teachers, and students' academic self-perception were significantly higher in private compared to public medical schools. However, students' perceptions of atmosphere and students' social self-perception were non-significant. 


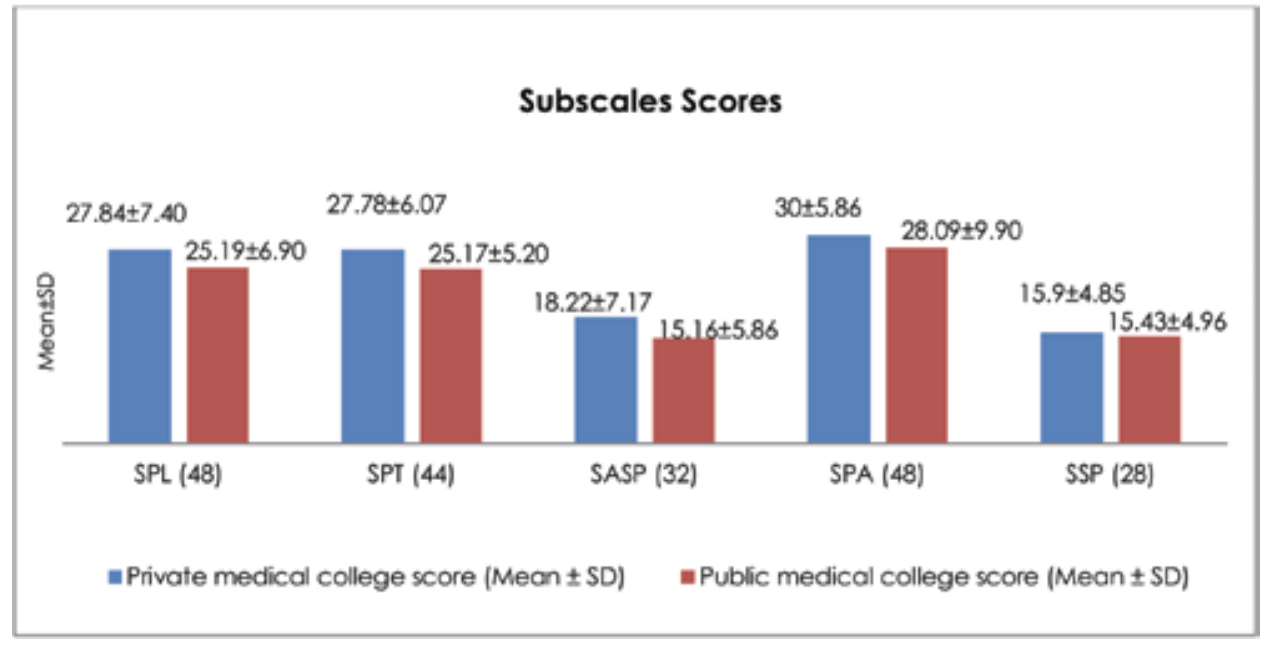

Figure 1: Scores of subscales in private versus public medical colleges in Pakistan.

SPL: Student perception of learning SPT: Student perception of teaching SASP: Student Academic self-perception SPA: Student perception of atmosphere SSP: Student social perception Number of students are shown in parenthesis.

Table 1 shows the mean scores of items in students' perception of learning (SPL). The mean score of SPL was in the range of $25-36$ indicating a positive approach' with a mean score of $27.84 \pm 7.40$ in private and $25.19 \pm 6.9$ in public medical college respectively. Student-centered approach, provision of learning outcomes from the beginning of the session, encouragement to participate in online sessions which stimulated learning were the items that were scored significantly higher for private compared with public medical schools. Students of private institutes having integrated curriculum found teaching to be more stimulating, student-centered, well focused with clear learning objectives than students from public medical colleges following traditional, non-integrated curriculum.

Table 1: Mean scores of items in Students' Perception of Learning (SPA).

\begin{tabular}{|l|c|c|c|}
\hline Items & $\begin{array}{c}\text { Private medical college } \\
\text { score } \\
\text { Mean } \pm \text { S.D (n=84) }\end{array}$ & $\begin{array}{c}\text { Public medical college } \\
\text { score } \\
\text { Mean } \pm \text { S.D (n=62) }\end{array}$ & p-Value \\
\hline $\begin{array}{l}\text { I'm encouraged to participate in } \\
\text { online/physical teaching sessions }\end{array}$ & $2.75 \pm 1.01$ & $2.44 \pm 0.88$ & $0.05^{*}$ \\
\hline Teaching methods stimulated learning & $2.75 \pm 1.05$ & $2.32 \pm 1.02$ & $0.015^{*}$ \\
\hline $\begin{array}{l}\text { Teaching involves active learning and is } \\
\text { student-centered }\end{array}$ & $2.76 \pm 1.01$ & $2.23 \pm 0.98$ & $0.002^{*}$ \\
\hline Teaching helps to develop my competence & $2.77 \pm 1.05$ & $2.55 \pm 1.21$ & 0.233 \\
\hline $\begin{array}{l}\text { Teaching is done by webinar, zoom, google } \\
\text { classroom and is well focused }\end{array}$ & $2.92 \pm 1.03$ & $2.50 \pm 1.02$ & 0.017 \\
\hline Teaching helps increase my confidencelevel & $2.52 \pm 1.18$ & $2.45 \pm 1.16$ & 0.715 \\
\hline $\begin{array}{l}\text { Teaching takes place regularly and time is } \\
\text { used efficiently }\end{array}$ & $2.74 \pm 1.08$ & $2.55 \pm 1.11$ & 0.30 \\
\hline Teaching is focused on basic learning* & $1.4 \pm 0.99$ & $1.53 \pm 1.00$ & 0.44 \\
\hline $\begin{array}{l}\text { Learning outcomes of the course are clear } \\
\text { from the beginning }\end{array}$ & $2.82 \pm 1.13$ & $2.35 \pm 1.02$ & $0.01^{*}$ \\
\hline $\begin{array}{l}\text { Teaching modules are designed to } \\
\text { encourage brainstorming by the students }\end{array}$ & $2.65 \pm 1.16$ & $2.50 \pm 1.12$ & 0.42 \\
\hline Teaching encourages long term learning & $2.54 \pm 1.14$ & $2.48 \pm 1.25$ & 0.79 \\
\hline Teaching is didactic and teachercentered* & $1.96 \pm 1.15$ & $1.73 \pm 1.04$ & 0.20 \\
\hline
\end{tabular}

*Significant values.

Figures $2 \mathrm{~A}$ and $\mathrm{B}$ show the mean scores of items in students' perception of the atmosphere (SPA) and student perception of teacher (SPT). The mean scores of the SPA were $30 \pm 9.38$ and $28.09 \pm 9.9$ in private and public colleges respectively which indicates a comfortable atmosphere. Students at private institutes felt more comfortable socially in class and considered the environment to be more relaxed during tutorials/PBLs. 


\section{$2 \mathrm{~A}$ \\ Mean Scores of Items (Students' Perception of Atmosphere)}

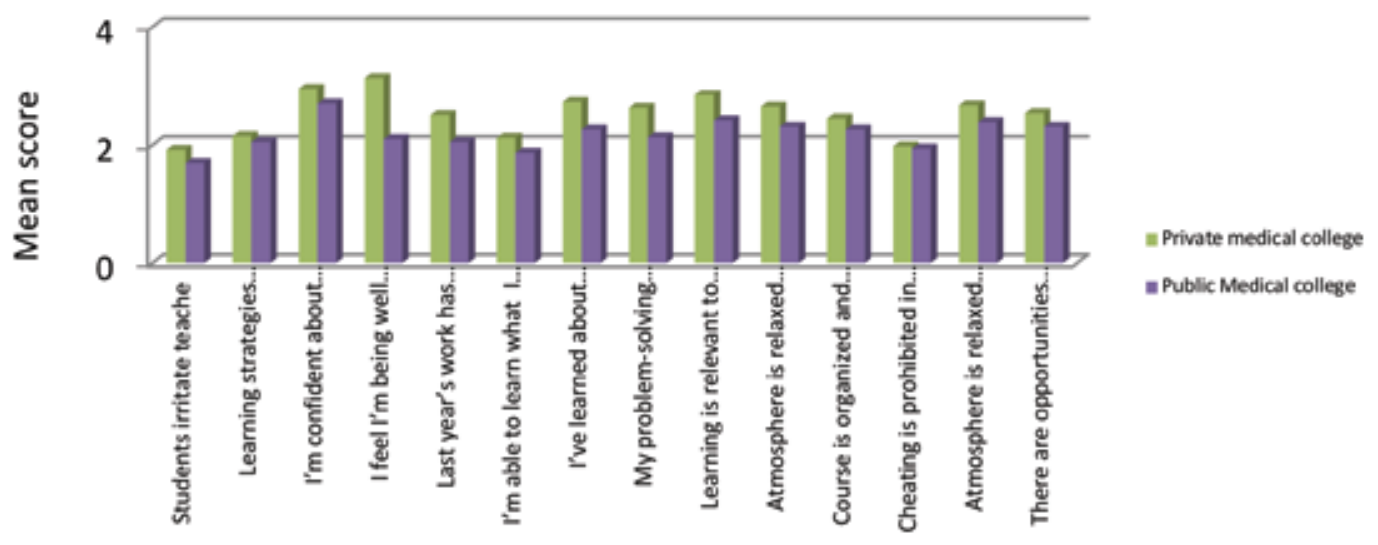

\section{B \\ Mean Scores of Items (Students' Perception of Teacher)}

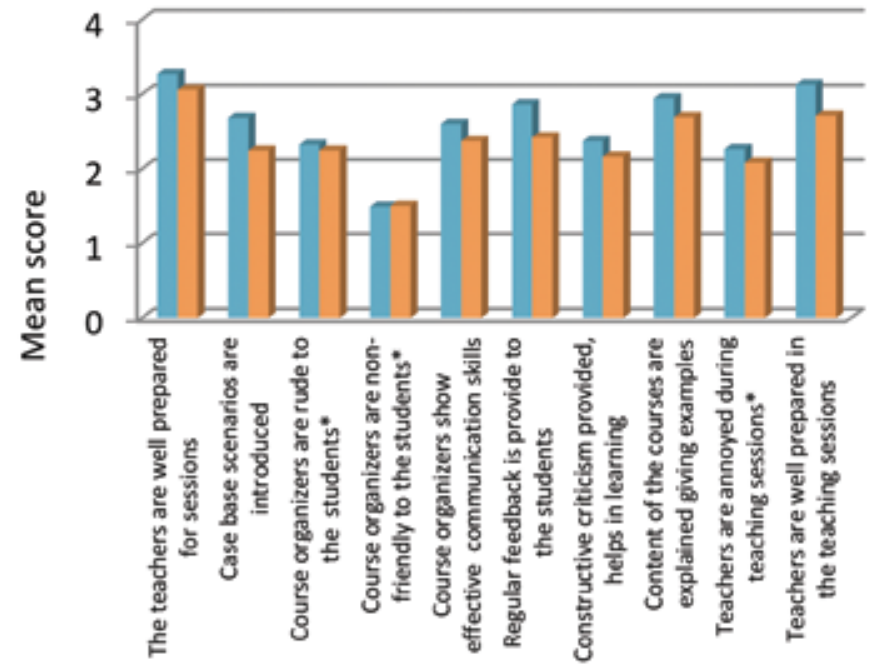

= Private medical college mean

Figure 2A and 2B: Mean scores of items in students' perception of atmosphere and students' perception of the teacher.

The mean score of SPT was $27.78 \pm 6.07$ and $25.17 \pm 5.2$ in private and public colleges respectively (Figure $2 B$ ). All the statements were comparable in both private and public sector medical institutions except those students from private medical schools felt teachers follow more case-based approaches even in the online learning method. They also felt that teachers are better at providing immediate feedback to students and teachers come prepared for class as compared to their fellows at public institutes.

Figures $3 A$ and $B$ show the mean scores of students' academic self-perception (SASP) and students' social self-perception (SSP). Mean scores of SPAP
18.22 \pm 7.17 and $15.16 \pm 5.86$ in private and public medical schools respectively. Students registered with private medical institutions following integrated curriculum felt that they were better prepared for their future professional career and learning about empathy in their profession. They also considered their problem-solving skills are better developed and they find the course they are studying, more useful and relevant to their healthcare career. The mean score of SSP was $15.90 \pm 4.85$ for private and $15.45 \pm 4.85$ for public medical colleges (Figure 3B). Students of private medical schools felt that they have a better support system for those who get stressed out. 

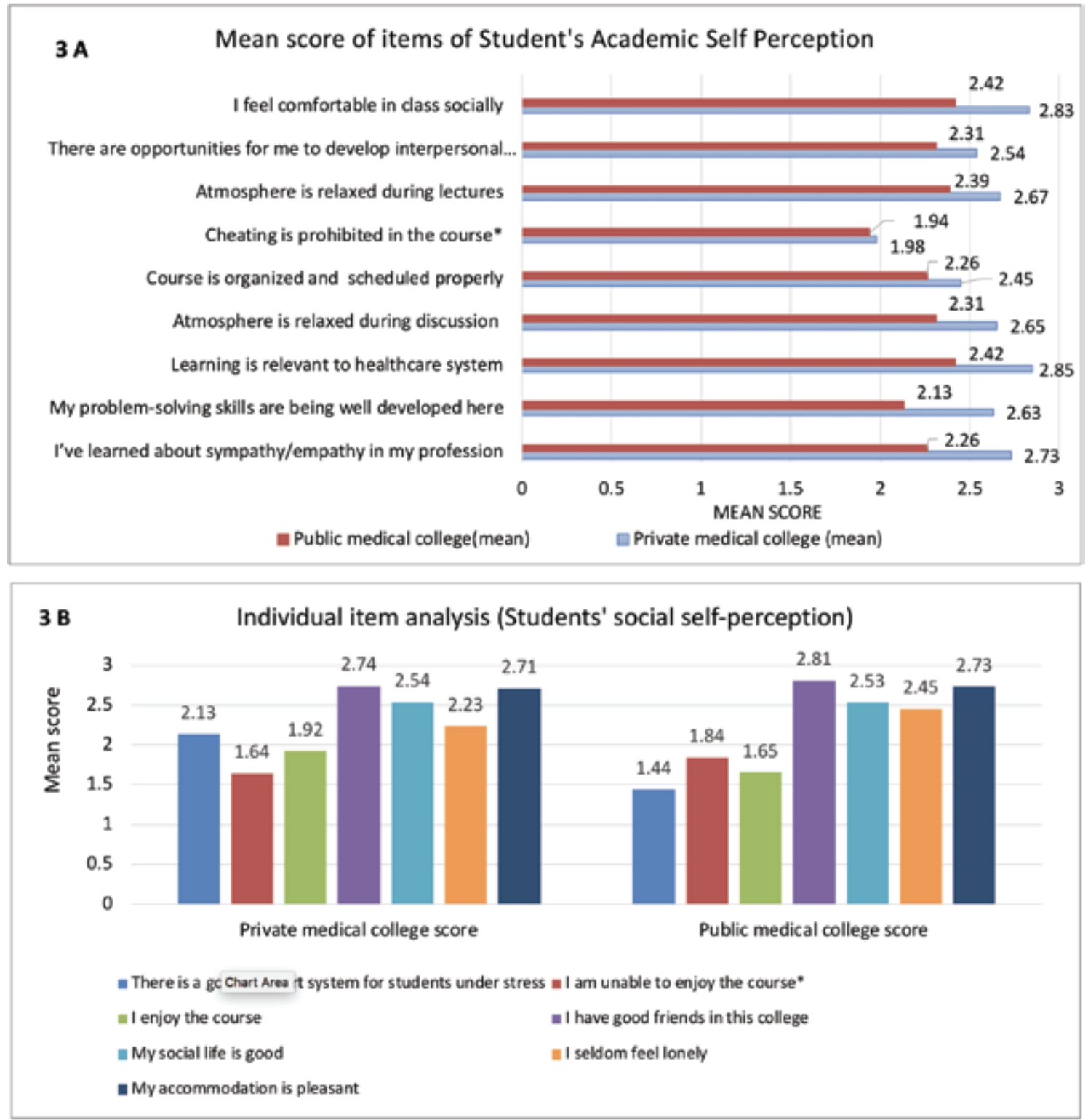

Figure 3A and 3B: Mean scores of items (Students' academic self-perception and students' social self-perception).

\section{DISCUSSION}

The study was focused to compare the learning environment between the public and private medical colleges of Lahore with traditional and integrated curriculum. Also, to identify the strengths and weaknesses of the institutions regarding the learning environment which may serve as the basis for further improvement of medical education in medical schools of Lahore, Pakistan. This study describes the total DREEM score of $122.60 \pm 29.31$ in private and $111.48 \pm 25.16$ in public medical schools in Lahore, which showed more positive.

The total score is comparable to previous studies conducted individually in private and public medical colleges of Pakistan which showed a score of
117 and 111 respectively 16,17 . A similar study was conducted in Faisalabad medical college, Pakistan ${ }^{15}$. The results were also comparable to the studies conducted in Germany, Bangladesh, Saudi Arabia, and Iran ${ }^{18-21}$. A study conducted in South Korea compared 40 different medical colleges and collected responses of over 9000 students with an overall mean DREEM'S score of 113.97 (out of 200) ${ }^{22}$. According to a study in 2019, DREEM's scores for medical and dental students are higher than nursing students which have a nonintegrated curric$u^{\prime} \mathrm{m}^{14}$. Another study conducted in Thailand across 34 teaching hospitals showed the educational environment to be more positive than negative with a mean score of 131.1 (SD=17.4) and concluded that students were satisfied with their educational 
environment ${ }^{23}$. The scores in our study were high compared to international studies done, which may be due to the better perception of their institutions by the students as they met their expectations.

Individual domain scores showed that there is an area of improvement in students' academic self-perception (SASP) and students' self-perception (SSP) in public sector medical schools. The learning strategies, problem-solving, and memorization skills need to be improved by including problem-based learning (PBLs) and small group discussions (SGDs) in traditional style teaching methodology. PBL and SGDs help improve the long-term learning capabilities $^{24}$. Also, support groups should be provided to the students. In the private sector on another hand, there is a vital need for betterment in the area of student self-perception (SSP) which needs similar improvement to be made as in the public sector.

Analysis of subscales revealed that the highest scores rated in private medical colleges were that "teaching is well focused" and "teachers are well prepared for their teaching sessions" which proves students' satisfaction with the teachers along with their teaching methodology. On the other hand, in the public sector the highest-rated questions were "I have good friends in this college" and "the teachers are knowledgeable," depicting that the public institutions are ensuring future satisfaction to students and a friendly environment. Students of both public and private institutions think that the lacking points of institutions are that the "course organizers are authoritarian" and "teaching over emphasizes factual learning," which point toward the need to shift from rote learning to clinical-based learning along with better student-teacher relationship for delivering the lectures during visiting the medical wards ${ }^{22}$. A study held in India signified differences between high and low academic scores, showing positive perceptions of high achievers regarding teachers, academic atmosphere, and social self-perceptions compared to the under-achievers ${ }^{23}$.

The most significant statements from private medical schools were that "teaching is often stimulating," "teachers are good at providing feedback to the students," teachers are well prepared for their teaching sessions," "I have learned a lot about empathy in my profession," "my problem-solving skills are being well developed here," and "there is a good support system for the students who get stressed." Our study had some limitations the effect of institutional size on the learning environment had not been evaluated. Some evidence from research suggests a favorable learning environment in small-sized medical schools as it can increase teacher-student interaction and increase learning opportunities for students ${ }^{24}$. Based on the findings of the study public sector medical schools may focus on students' perception of learning (SPL), students' perception of teachers (SPT), and students' academic self-perception (SASP), and private medical schools should focus on Student's perception of the atmosphere (SPA) and student's social self-perception (SSP) to improve the learning environment for medical students.

\section{CONCLUSION}

The learning environment in both medical colleges' private and public colleges was perceived as conducive during Covid-19. A more significant perception was obtained from private-sector medical students regarding students' perception of learning (SPL), students' perception of teachers (SPT), and students' academic self-perception (SASP) as compared to public medical colleges. However, students' perceptions of the atmosphere (SPA) and student social self-perception (SSP) were non-significant between both groups.

\section{ACKNOWLEDGEMENTS}

We owe thanks to Prof Dr. Zahid Bashir Principal Shalamar Medical and Dental College for encouraging medical students for conducting research.

\section{CONFLICT OF INTEREST}

The authors declare no conflict of interest.

\section{ETHICS APPROVAL}

Ethics approval was obtained from the IRB committee of Shalamar Medical and Dental College, Lahore.

\section{PARTICIPANT'S CONSENT}

Written consent was obtained from the participants of the study.

\section{AUTHORS' CONTRIBUTION}

All authors contributed equally to this research writeup.

\section{REFERENCES}

1. Genn JM. AMEE Medical Education Guide No. 23 (Part 1): Curriculum, environment, climate, quality and change in medical education-a unifying perspective. Med Teach. 2001;23(4):337-344. doi: 10.1080/01421590120063330

2. Salam A, Yousuf R, Bakar SM, Haque M. Stress among medical students in Malaysia: A systematic review of literatures. Int Med J. 2013;20(6):649-655.

3. Tackett S, Wright S, Lubin R, Li J, Pan H. International study of medical school learning environments and their relationship with student well-being and empathy. Med Educ. 2017;51(3):280-289. doi: 10.1111/medu. 13120

4. Tackett S, Bakar HA, Shilkofski NA, Coady N, Rampal K, Wright S. Profiling medical school learning environments in Malaysia: a validation study of 
the Johns Hopkins Learning Environment Scale. J Educ Eval Health Prof. 2015;12:1-7. doi: 10.3352/jeehp.2015.12.39

5. Irfan F, Al Faris E, Al Maflehi N, Karim SI, Ponnamperuma G, Saad H, Ahmed AM. The learning environment of four undergraduate health professional schools: Lessons learned. Pak J Med Sci. 2019; 35(3): 598-604. doi: 10.12669/pjms.35.3.712

6. Rehman R, Ghias K, Fatima SS, Hussain M, Alam F. Dream of a conducive learning environment: One DREEM for all medical students! J Pak Med Assoc. 2017:67(1):7-11.

7. Qin Y, Wang Y, Floden RE. The effect of problem-based learning on improvement of the medical educational environment: a systematic review and meta-analysis. Med Princ Pract. 2016;25(6):525-532. doi: $10.1159 / 000449036$

8. Shochet RB, Colbert-Getz JM, Wright SM. The Johns Hopkins learning environment scale: measuring medical students' perceptions of the processes supporting professional formation. Acad Med. 2015;90(6):810-818. doi: 10.1097/ACM.000000000000 0706

9. Chan CY, Sum MY, Tan GM, Tor PC, Sim K. Adoption and correlates of the Dundee ready educational environment measure (DREEM) in the evaluation of undergraduate learning environments-a systematic review. Med Teach. 2018;40(12):1240-1247. doi: 10.1080/0142159X.2018.1426842

10. Miles S, Swift L, Leinster SJ. The Dundee Ready Education Environment Measure (DREEM): a review of its adoption and use. Med Teach. 2012;34(9):620-634. doi: 10.3109/0142159X.2012.668625

11. Kim $H$, Jeong $H$, Jeon $P$, Kim S, Park YB, Kang $Y$. Perception study of traditional Korean medical students on the medical education using the Dundee ready educational environment measure. Evid Based Complement Alternat Med. 2016;2016:1-7. doi: 10.1155/2016/6042967

12. Imran N, Khalid F, Haider II, Jawaid M, Irfan $M$, Mahmood A, et al. Student's perceptions of educational environment across multiple undergraduate medical institutions in Pakistan using DREEM inventory. J Pak Med Assoc. 2015;65(1):24-28.

13. Ali K, Raja M, Watson G, Coombes L, Heffernan E. The dental school learning milieu: students' perceptions at five academic dental institutions in Pakistan. J Dent Educ. 2012;76(4):487-494. doi: 10.1002/j.0022-0337.2012.76.4.tb05281.x

14. Ahmed W, Tufail S, Nawaz H, Sana N, Shamim H. Evaluation of educational environment of nursing undergraduates based on DREEM model in institute of nursing, CMH Lahore Medical College. Pak Armed Forces Med J. 2016;66(3):444-448.

15. Umber A, Khan S, Ihsan S. Educational Environment at University Medical and Dental College, FSD. Ann King Edw Med Univ. 201 1;17(3):292-298.

16. Khursheed I, Baig L. Students' perceptions of educational environment of a private medical school in Pakistan. J Pak Med Assoc. 2014;64(1 1):1244-1249.

17. Jawaid M, Raheel S, Ahmed F, Aijaz H. Students' perception of educational environment at Public Sector Medical University of Pakistan. J Res Med Sci. 2013; 18(5): 417-421.

18. Ostapczuk MS, Hugger A, De Bruin J, Ritz-Timme $S$, Rotthoff T. DREEM on, dentists! Students' perceptions of the educational environment in a German dental school as measured by the Dundee Ready Education Environment Measure. Eur J Dent Educ. 2012;16(2):67-77. doi: 10.1111/j.1600-0579.2011.007 20.x

19. Mostafa A, Hoque R, Haque M. Student-based analysis of perception regarding the educational environment using the Dundee Ready Education Environment Measure questionnaire at Chattagram Maa-O-Shishu Hospital Medical College, Bangladesh. Florence Nightingale Hemsire Derg. 2019; 27(3): $211-221$. doi: 10.5152/FNJN.2019.19025

20. Sabbagh HJ, Bakhaider HA, Abokhashabah HM, Bader MU. Students' perceptions of the educational environment at King Abdulaziz University Faculty of Dentistry (KAUFD): a cross sectional study. BMC Med Educ. 2020;20(1):1-7. doi: doi.org/10.1186/s12909020-02165-7

21. Bakhshi $H$, Bakhshialiabad $M H$, Hassanshahi $G$. Students' perceptions of the educational environment in an Iranian Medical School, as measured by the Dundee Ready Education Environment Measure. Bangladesh Med Res Counc Bull. 2014;40(1):36-41. doi: 10.3329/bmrcb.v40i1.20335

22. Hongkan W, Arora R, Muenpa R, Chamnan P. Perception of educational environment among medical students in Thailand. Int J Med Educ. 2018; 9: 18-23. doi: 10.51 16/ijme.5a4a.1eda

23. Simamora RE, Sidabutar DR, Surya E. Improving learning activity and students' problem solving skill through problem based learning (PBL) in junior high school. Int J Sci Basic Appl Res. 2017;33(2):321-331. 24. Mayya S, Roff S. Students' perceptions of educational environment: a comparison of academic achievers and under-achievers at Kasturba Medical College, India. Educ Health. 2004;17(3):280-291. doi: 10.1080/13576280400002445. 